\title{
BНУТРЕННИЕ БОЛЕЗНИ INTERNAL DISEASES
}

УДК: 615.849.19:616.36-002

DOI

\section{ЛАЗЕРНАЯ ТЕРАПИЯ В ЛЕЧЕНИИ ХРОНИЧЕСКИХ ВИРУСНЫХ ГЕПАТИТОВ}

\section{LASER THERAPY IN CHRONIC VIRAL HEPATITIS TREATMENT}

\author{
Н.М. Бурдули, А.С. Крифариди, И.З. Аксенова \\ N.M. Burduli, A.S. Krifaridi, I.Z. Aksenova \\ Северо-Осетинская государственная Медицинская Академия, \\ Россия, 362019, РСО - Алания, г. Владикавказ, ул. Пушкинская, 40 \\ North Ossetian State Medical Academy, \\ 40 Pushkinskaya St, Vladikavkaz, Republic of North Ossetia-Alania \\ E-mail: burduli@yandex.ru, anastasya.krifaridi@yandex.ru,crocon@mail.ru
}

\begin{abstract}
Аннотация
Целью работы было изучение влияния низкоинтенсивного лазерного излучения на эндотелию сосудов - суммарные метаболиты оксида, состояние капиллярного кровотока. Участвующие в исследовании пациенты были разделены на три группы: в первой (контрольной) группе (30 человек), для лечения использовалась только традиционная медикаментозная терапия; больные второй группы (основная группа, 85 человек) наряду с медикаментозной терапией получали курс внутривенной лазерной терапии и третья группа больных (основная группа, 45 человек), получала курс накожной лазерной терапии. Результаты нашего исследования свидетельствуют, что медикаментозная терапия больных хроническими вирусными гепатитами не сопровождается достоверным улучшением содержания в плазме крови метаболитов оксида азота, а также показателей микроциркуляции, а включение в комплекс лечебных мероприятий лазерной терапии способствует достоверному улучшению показателей капиллярного кровотока и дисфункции эндотелия сосудов у пациентов с хроническими гепатитами. Нами доказано, что различные методы лазерной терапии положительно влияют на функциональное состояние сосудистого эндотелия, способствуют коррекции выявленных нарушений кровотока.
\end{abstract}

\begin{abstract}
The aim of the work was to study the effect of low-intensity laser radiation on the vascular endotheliumtotal oxide metabolites, and the state of capillary blood flow. The patients participating in the study were divided into three groups: in the first (control) group (30 people), only traditional drug therapy was used for treatment, patients of the second group (the main group, 85 people) received a course of intravenous laser therapy along with medication, and the third group of patients (the main group, 45 people) received a course of cutaneous laser therapy. The results of our study show that drug therapy of patients with chronic viral hepatitis is not accompanied by credible improvements to the content in blood plasma nitric oxide metabolites, and indicators of microcirculation, and the inclusion in the complex treatment of laser therapy provides statistically significant performance improvement in capillary blood flow and dysfunction of vascular endothelium.
\end{abstract}

Ключевые слова: дисфункция эндотелия, микроциркуляция, оксид азота, хронический гепатит, лазерная терапия низкой интенсивности.

Keywords: endothelial dysfunction, microcirculation, nitric oxide, chronic hepatitis, low-intensity laser therapy. 


\section{Введение}

Хронические вирусные гепатиты стали тяжелым бременем в XX веке - неуклонный рост заболеваемости, развитие летальных осложнений, высокая медико-социальная значимость, несмотря на создание новых, высокоэффективных методов лечебного воздействия [Ахмедов, 2011; Ивашкин, Лапина, 2012].

Развитие хронических воспалительных заболеваний печени происходит в соответствии с фундаментальными патофизиологическими синдромами, такими как повреждение, репарация и фиброзирование, хроническое воспаление, пролиферация, опухолевое перерождение, иные нарушения. С развитием представлений о патогенезе хронических воспалительных заболеваний печени и/или их осложнений в центре внимания оказались исследования о роли эндотелия и его дисфункции.

Функция эндотелия как общебиологического регулятора определяется сбалансированной продукцией биологически активных веществ, гормонов, гуморальных факторов локального и системного действия - лишь часть из них изучена детально (оксид азота как клинический критерий функционального состояния эндотелия, комплекс мощных вазоконстрикторов (эндотелины, ангиотензин II), цитокины). С клинико-экспериментальной точки зрения особая роль отводится оксиду азота - основному регулятору и индикатору функциональной активности эндотелия. Такие доказанные эффекты NO, как антимикробной, противоопухолевой и регуляторный про-противовоспалительный определяют динамику острых и хронических воспалительных, дегенеративных и опухолевых процессов. [Звягинцева, Гриднева, 2005; Марков, 2011].

Дисфункция эндотелия в клинической практике оценивается по нарушению соотношения вышеуказанных сосудорасширяющих/суживающих факторов и эффектов.

Эндотелий и/или эндотелиальная дисфункция (endothelial dysfunction, ED) имеют фундаментальное значение в развитии, динамике, течении острых и хронических заболеваний. Изучение роли эндотелия в патологии печени привело к разработке и использованию методов патогенетической коррекции ED. В свете указанных фактов одним из лучших по соотношению пользы и безопасности, стоимости и доступности методов выступает коррекция нарушений функции эндотелия различными методами лазерной терапии. [Аксенова, Бурдули, 2015; Абакумов, Голиков, 2005; Загидуллин и др., 2010].

Поливалентные эффекты лазерного облучения приводят и к существенным изменениям патологических нарушений системы тканевой гемодинамики. Отмечаемые у больных хроническим гепатитом нарушения тканевой перфузии являются патогенетическим звеном патологического процесса в печени. Так нарушения капиллярного баланса в печени способствуют усугублению воспалительного процесса, являются одним из существенных факторов развития некроза печени, что существенно усугубляет его течение [Бурдули, Крифариди, 2009; Васильев и др., 2003; Козлов, 2006; Жаров и др., 2001; Пахомов, Вчерашний, 2016; Маколкин, Подзолков, Павлов, Богданова, 2000].

Гемодинамические расстройства могут способствовать хронизации патологического процесса, служить причиной многих тяжелых осложнений [Гейниц, Цыганова, 2011; Манапова и др., 2005; Маколкин и др., 2000]. Остаются еще недостаточно изученными многие вопросы взаимодействия лазерной терапии на уровне терминального сосудистого русла [Гейниц и др., 2006; Козлов, Азизов, 2011; Каменская и др., 2011; Применение лазерной доплеровской флоуметрии в медицинской практике, 1998].

Цель работы. Оценка наличия и степени выраженности капиллярных нарушений, изучение содержания в плазме крови больных стабильных метаболитов оксида азота, нитратов и нитритов (NOx) у больных хроническими вирусными гепатитами и воздействие лазерной терапии на эти показатели. 


\section{Материалы и методы обследования}

Проведено динамическое наблюдение 160 пациентов хроническими вирусными гепатитами. Гендерное соотношение: 37 женщин (21,5\%) и 123 мужчин (78,5 \%). Средний возраст больных составил 43,4 \pm 8,6 лет.

Динамическое наблюдение пациентов осуществлялось путем клинического и комплексного лабораторно-инструментального исследования, включая ультразвуковое исследование брюшной полости, эластометрию печени, лабораторные тесты, ИФА-анализ (тестирование маркеров вирусов гепатита). Соотношение пациентов по этиологическому фактору: HCV - 76,7 \%, HBV - 23,3 \%. Отсутствие репликации вируса подтверждено методом молекулярно-биологического тестирования (ПЦР), что обосновало от противовирусной терапии на момент наблюдения [Крифариди, 2008].

Динамическое наблюдение проводилось в трех сопоставимых группах пациентов:

- группа первая (группа контроля, контрольная группа) - 30 человек, традиционная медикаментозная комплексная терапия (дезинтоксикационная гепатопротективная, симптоматическая и метаболическая);

- группа вторая (основная группа) - 85 человек, пациентам проводилась комплексная терапия с включением традиционной медикаментозной и курса внутривенного лазерного облучения крови. Внутривенное лазерное облучение крови проводилось в виде сеансов продолжительностью 20 минут, 7 раз, ежедневно (аппарат «Мулат», ТЕХНИКА, длина волны лазера 0,63 мкм, выходящая мощность на конце световода 1,5-2 мВт.).

- группа третья (основная группа) - 45 пациентам осуществлялось комплексная терапия с включением традиционной медикаментозной и курса накожной лазерной терапии. Накожная лазерная терапия проводилась в виде сеансов с использованием контактно - стабильной методики, 10 раз, ежедневно (аппарат «Мустанг-БИО», ТЕХНИКА, длина волны лазера 0,89 мкм, частота - 80 Гц, мощность 6,5 Вт, воздействие на 1 поле - 60-90 сек.) [Крифариди, 2008].

Исследование баланса нитрат/нитритной системы проводилось колориметрическим методом (реакция диазотирования нитритом сульфаниламида, реактив Грисса), анализатор Victor2 фирмы Perkin Elmer (Финляндия) [Крифариди, 2008].

Тканевая перфузия (капиллярный кровоток) тестирован с помощью лазерной допплеровской флоуметрии (ЛДФ), прибор ЛАКК - 02 (ООО НПП «Лазма».

Анализ показателей капиллярного кровотока осуществлен как в покое (базальный кровоток), так и при проведении функциональной окклюзионной пробы на основании следующих данных:

- показатель микроциркуляции - ПМ;

- амплитуда низкочастотных колебаний кровотока - ALF;

- амплитуда высокочастотных колебаний кровотока - AHF;

- пассивные механизмы капиллярного кровотока - ACF;

- пиковый ПМ;

- резерв капиллярного кровотока.

По результатам интегрального анализа показателей базального кровотока и окклюзионной пробы (ОП) выделены четыре гемодинамических типа капиллярного кровотока:

- гиперемический;

- нормоциркуляторный;

- спастический;

- застойно-стазический.

Гемодинамический тип капиллярного кровотока - соотношение ПМ в покое и резерв капиллярного кровотока при проведении окклюзионной пробы.

Данные обработаны статистическими программами. 


\section{Результаты и их обсуждение}

Разнонаправленные, а порой и противоположные изменения у пациентов сопоставимых групп (при хронических вирусных гепатитах отмечены нами ранее в функциональной системе тромбообразования и свертывания крови, соотношения про- и противоспалительных медиаторов плазмы, сосудосуживающих/сосудорасширяющих веществ) свидетельствуют о сложном индивидуальном сочетании патогенетических механизмов.

Результаты исследования маркеров эндотелиальной функции/дисфункции представлены на рисунке 1. Преимущественно во всех группах отмечается повышение NOx.

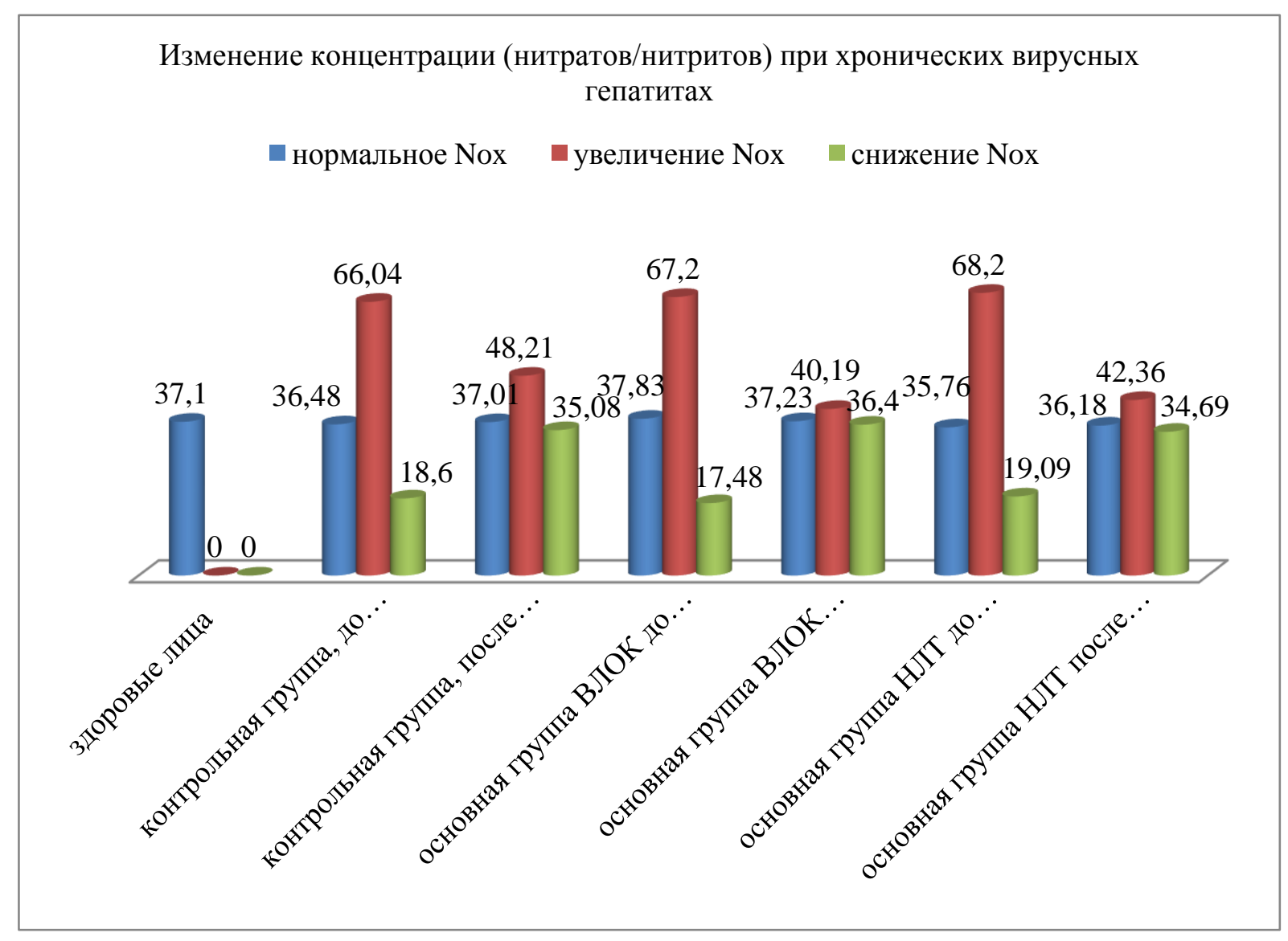

Рис. 1. Изменение концентрации (нитратов/нитритов) при хронических вирусных гепатитах

Fig. 1. NOx (nitrate/nitrite) blood level in chronic viral hepatitis

В контрольной/первой группе (рис. 1), на фоне традиционной медикаментозной терапии, содержание метаболитов оксида азота имеет недостоверную тенденцию к снижению/нормализации. При достоверно сниженном содержании нитратов и нитритов после лечения увеличился показатель до $35,08 \pm 5,3$ мкм/л $(\mathrm{p}<0,05)$, но не достиг нормальных величин. Таким образом, степень патологических отклонений содержания в организме NOx является динамичным параметром, косвенно свидетельствующим о степени контроля над заболеванием. По мере проявления эффектов патогенетической терапии показатели NOx приближаются к нормальным значениям.

Во второй группе (комбинированная терапия с использованием метода внутривенного лазерного облучения крови) избыточный уровень нитратов/нитритов в динамике достоверно снизился до 40,19 2,8 мкмоль/л $(\mathrm{p}<0,01)$. Пониженный до лечения уровень метаболитов оксида азота $-17,48 \pm 4,2$ мкмоль/л после лечения достоверно увеличился до $36,4 \pm 2,5$ мкмоль/л $(\mathrm{p}<0,001)$.

Имеет место коррекция системы оксида азота и дисфункции эндотелия под влиянием лазерной терапии низкой интенсивности, эффект следует считать самостоятельным и независимым. 
В третьей группе (комбинированная терапия с использованием метода накожного лазерного облучения крови) избыточная концентрация метаболитов оксида азота уменьшается до 42,36 \pm 7,2 мкмоль/л $(\mathrm{p}<0,05)$. Состояние эндотелиальной функции достоверно улучшается также у пациентов, получавших НЛТ при исходно низком содержании NOx.

Таким образом, традиционная медикаментозная терапия недостоверно восстанавливает концентрации маркеров функции эндотелия. Лазерная терапия обладает самостоятельным, независимым, корригирующим действием на функцию эндотелия и концентрацию суммарных метаболитов оксида азота у пациентов с хроническими вирусными гепатитами.

При исследовании капиллярного кровотока в процессе лечения у исследуемых пациентов были выявлены следующие гемодинамические типы (рис. 2).

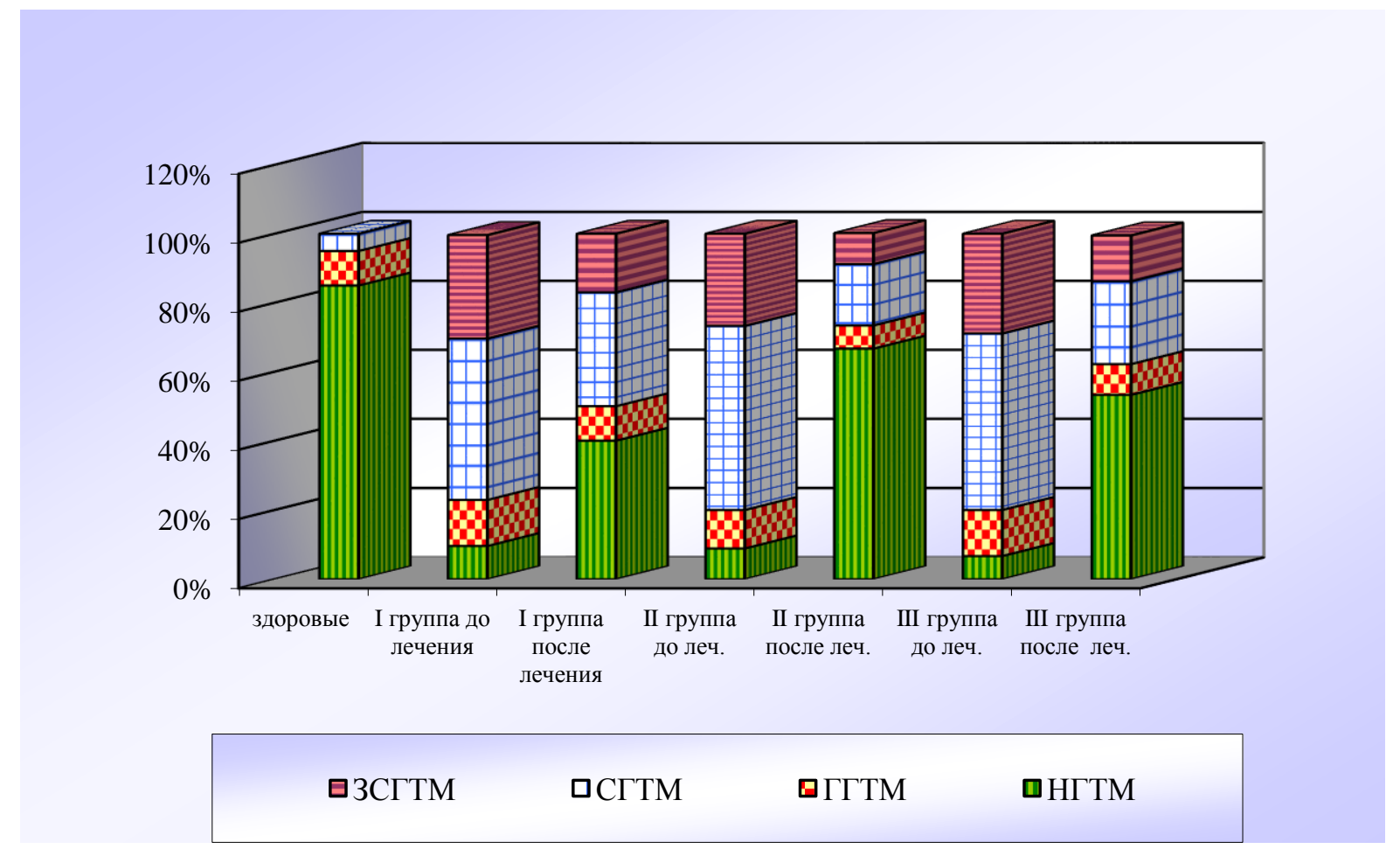

Рис. 2. Структура капиллярного кровотока при хроническом вирусном гепатите до и после лечения

Fig. 2. Microcirculation in patients with HCG before and after treatment

Как следует из полученных данных (рис. 2), у пациентов с хроническими гепатитами отмечаются существенные нарушения тканевой перфузии, доминирующими типами микроциркуляции являются неоптимальные/патологические: спастический (СГТМ), гиперемический (ГГТМ), застойно-стазический (ЗСГТМ), которые отражают комплекс разнообразных нейро-гуморальных и иных влияний на систему МКЦ при хроническом вирусном гепатите. Таким образом, можно заключить, что хронический вирусный гепатит на уровне капиллярного русла представляет собой гетерогенную группу. Тип микроциркуляции является динамической функцией, изменяясь на фоне естественного течения и/или лечения заболевания.

Статус капиллярного кровотока у больных хроническим гепатитом в ходе наблюдения представлен в таблице 1.

У небольшого количества пациентов во всех группах воздействия исходно наблюдался нормоциркуляторный тип (НГТМ) - эта сбалансированная система МКЦ не измени- 
лась и на фоне терапии (как медикаментозной, так и лазерной терапии низкой интенсивности), что подчеркивает положительные и безопасные эффекты терапии.

Таблица 1

Table 1

Статус капиллярного кровотока под влиянием лазерной терапии у пациентов с хроническими гепатитами

Status of capillary blood flow under the influence of laser therapy in patients with chronic hepatitis

\begin{tabular}{|c|c|c|c|c|c|}
\hline \multirow{2}{*}{$\begin{array}{c}\text { Параметры } \\
\text { микроцируляции } \\
\text { (норма) }\end{array}$} & \multirow{2}{*}{ Группа } & \multicolumn{2}{|c|}{ Нормоциркуляторный тип } & \multicolumn{2}{|c|}{ Гиперемический тип } \\
\hline & & До лечения & После лечения & До лечения & После лечения \\
\hline \multirow{3}{*}{$\begin{array}{c}\text { ПМ } \\
(4,82 \pm 0,1 \text { перф. } \\
\text { ед.) } \\
\end{array}$} & $\mathrm{I}$ & $5,1 \pm 0,5$ & $4,2 \pm 0,6$ & $7,4 \pm 1,26^{\#}$ & $4,7 \pm 0,96$ \\
\hline & II & $4,48 \pm 0,2$ & $4,77 \pm 0,5$ & $6,47 \pm 0,75^{\#}$ & $4,11 \pm 0,1^{* *}$ \\
\hline & III & $4,31 \pm 0,7$ & $4,5 \pm 0,6$ & $7,68 \pm 1,04^{\# \#}$ & $5,05 \pm 0,83^{*}$ \\
\hline \multirow{3}{*}{$\begin{array}{c}\text { РКК } \\
(265 \pm 25 \%)\end{array}$} & $\mathrm{I}$ & $280,4 \pm 20,1$ & $243,2 \pm 33,6$ & $173,7 \pm 12,6^{\# \#}$ & $296,3 \pm 49,5^{*}$ \\
\hline & II & $247,7 \pm 28,9$ & $261,9 \pm 29,8$ & $194,9 \pm 10,0^{\# \#}$ & $246 \pm 13,45^{* *}$ \\
\hline & III & $255 \pm 22,5$ & $260,5 \pm 17,5$ & $187,9 \pm 34,1$ & $310 \pm 10^{* *}$ \\
\hline \multirow{2}{*}{$\begin{array}{c}\text { Параметры } \\
\text { микроцируляции } \\
\text { (норма) }\end{array}$} & \multirow{2}{*}{ Группа } & \multicolumn{2}{|c|}{ Спастический } & \multicolumn{2}{|c|}{ Застойно-стазический } \\
\hline & & После лечения & До лечения & После лечения & После лечения \\
\hline \multirow{3}{*}{$\begin{array}{c}\text { ПМ } \\
(4,82 \pm 0,1 \text { перф. } \\
\text { ед.) }\end{array}$} & $\mathrm{I}$ & $2,66 \pm 0,8^{\# \#}$ & $2,96 \pm 0,5$ & $3,5 \pm 1,1$ & $3,85 \pm 0,82$ \\
\hline & II & 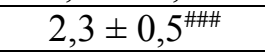 & $4,6 \pm 0,2^{* * * *}$ & $3,4 \pm 0,3^{\# \# \#}$ & $4,6 \pm 0,5^{*}$ \\
\hline & III & $2,39 \pm 0,4^{\# \# \#}$ & $3,55 \pm 0,3^{*}$ & $3,5 \pm 0,6^{\#}$ & $4,4 \pm 0,9$ \\
\hline \multirow{3}{*}{$\begin{array}{c}\text { РКК } \\
(265 \pm 25 \%)\end{array}$} & $\mathrm{I}$ & $417,6 \pm 57,1^{\#}$ & $330,5 \pm 51,2$ & $199,5 \pm 18,9^{\#}$ & $275,6 \pm 38,7$ \\
\hline & II & $445,4 \pm 44,4^{\# \#}$ & $297,2 \pm 37,2^{*}$ & $143,7 \pm 28,6^{\# \#}$ & $236,1 \pm 19^{* *}$ \\
\hline & III & $405,9 \pm 36^{\# \#}$ & $312,3 \pm 28^{*}$ & $194,43 \pm 24^{\#}$ & $270 \pm 20^{*}$ \\
\hline
\end{tabular}

Примечание: ${ }^{*} \mathrm{p}<0,05 ;{ }^{\# \#}<0,01 ;{ }^{\# \#} \mathrm{p}<0,001-$ различия с группой здоровых, ${ }^{*} \mathrm{p}<0,05$; $* * \mathrm{p}<0,01 ; * * * \mathrm{p}<0,001-$ различия до и после лечения в пределах одной группы.

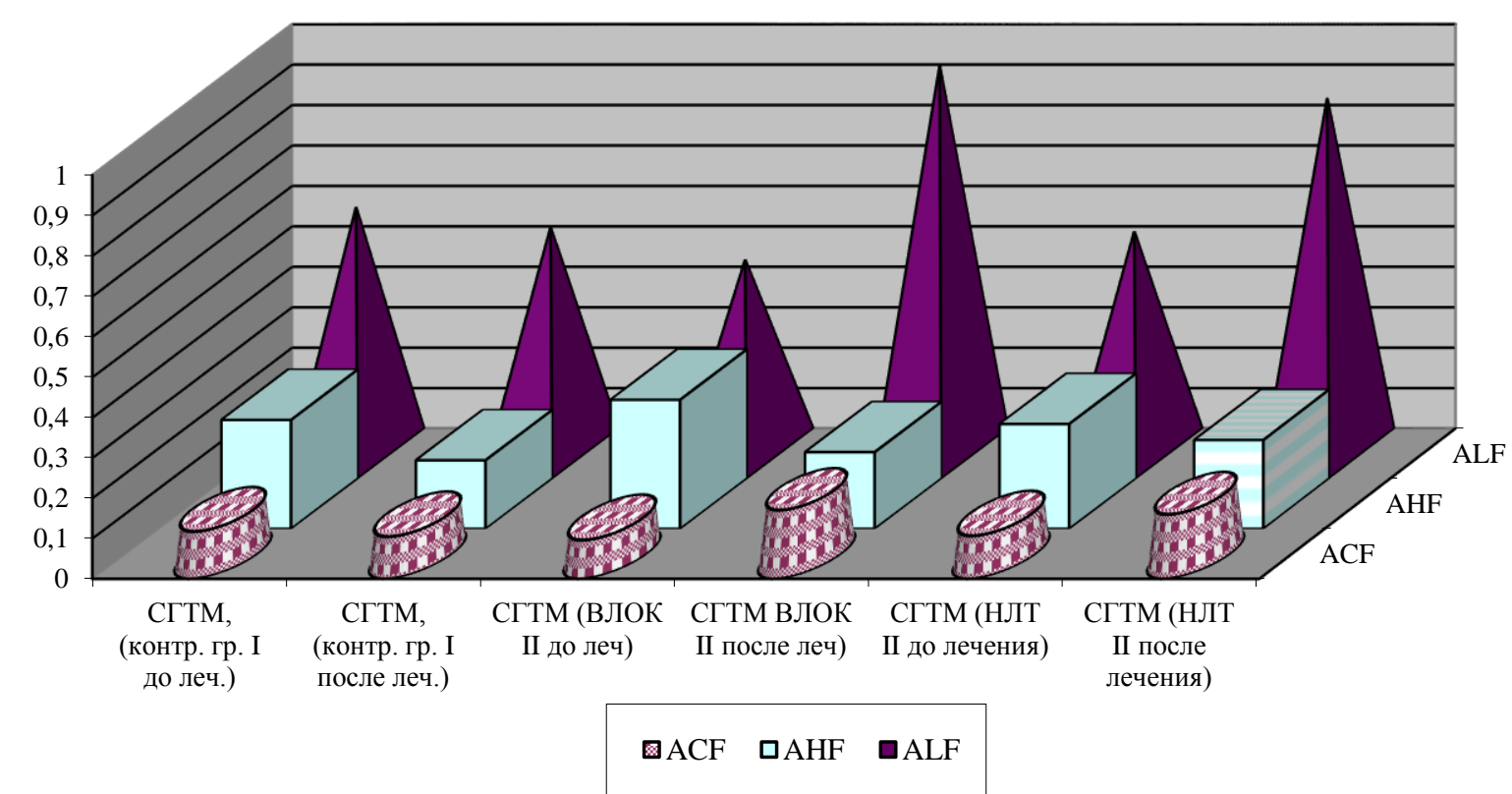

Рис. 3. Динамика показателей амплитудно-частотного спектра у пациентов с хроническим гепатитом с спастическим гемодинамическим типом микроциркуляции Fig. 3. Dynamics of parameters of the amplitude-frequency spectrum in patients with chronic hepatitis with spastic hemodynamic type of microcirculation 


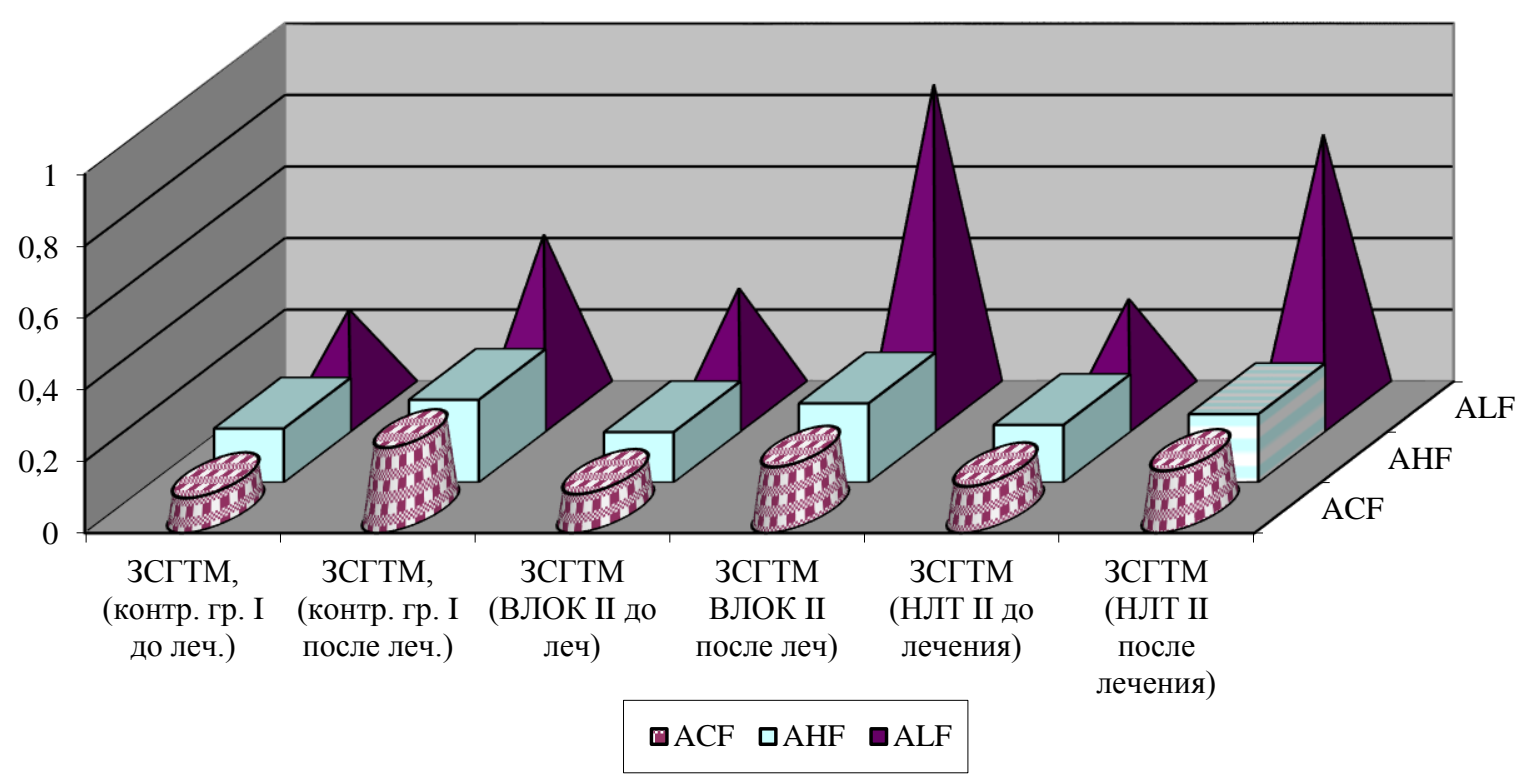

Рис. 4. Динамика показателей амплитудно-частотного спектра у пациентов с хроническим гепатитом с застойно-стазическим гемодинамическим типом микроциркуляции Fig. 4. Dynamics of parameters of the amplitude-frequency spectrum in patients with chronic hepatitis with stagnant-stasis hemodynamic type of microcirculation

Результаты исследования тканевой перфузии (показатели капиллярного кровотока) представлены ниже.

Застойная гиперемия при ГГТМ значительно снижалась на фоне лечения во всех исследуемых сопоставимых группах, что отражается в виде ряда параметров:

1. Нормализации/повышения исходно сниженного показателя микроциркуляции (ПМ). При этом в контрольной группе выявлена лишь тенденция, в обеих основных группах - достоверная положительная динамика ПМ. Являясь интегральным показателем тканевой перфузии, ПМ комплексно свидетельствует в пользу самостоятельного благоприятного нормализующего влияния лазерной терапии на функцию эндотелия и регуляцию капиллярного русла у данной категории пациентов (табл. 1).

2. Проведенный интегральный разбор амплитудно-частотного спектра (АЧС) в различных группах вмешательства пациентов с ГГТМ выявил закономерное снижение сосудистого тонуса микроциркуляторного русла, повышение показателей сверхмедленного ритма (A $)$, AHF (быстрые колебания капиллярного кровотока), доминирование пульсовых колебаний, что говорит о разбалансировании тканевой перфузии в пользу пассивных механизмов регуляции.

3. Анализ динамики показателей АЧС у пациентов с ГГТМ подтверждает самостоятельные корригирующие эффекты различных методов лазерной терапии, выявленных у пациентов основных групп, - у пациентов контрольной группы достоверного улучшения тканевой перфузии не произошло.

При выполнении функциональной окклюзионной пробы в группе больных с ГГТМ отмечается снижение резерва капиллярного кровотока, что свидетельствует об уменьшении количества резервных капилляров. В ходе лечения вышеуказанные показатели капиллярного кровотока улучшаются, причем достоверные положительные сдвиги происходят только при сочетанном использовании медикаментозной и лазерной терапии, что свидетельствует о самостоятельном положительном патогенетическом воздействии лазерного облучения, при хронических вирусных гепатитах различной этиологии. 
При исследовании показателей тканевой перфузии у пациентов с патологическим спастическим типом микроциркуляции (СГТМ) отмечается динамическое улучшение как на фоне традиционной терапии, так и у пациентов с использованием различным методов лазерной терапии, однако достоверность положительных сдвигов достигнута только у пациентов основных групп (ВЛОК и НЛТ). Так, анализ АЧС пациентов с СГТМ выявил на фоне лазерного лечения возрастание ALF колебаний, снижение амплитуды AHF колебаний (рис. 3), нормализацию показателей ПМ (табл. 1). Функциональная нормализация тканевой перфузии подтверждается восстановлением резерва капиллярного кровотока (РКК) на фоне лазерной терапии, изученного при проведении окклюзионной пробы (табл. 1).

Наиболее выраженные патологические показатели тканевой перфузии закономерно выявлены у пациентов с застойно-стазическим гемодинамическим типом микроциркуляции (рис. 4). Динамическое исследование показателей кровотока выявило:

- достоверное повышение/нормализацию ПМ на фоне лазерной терапии, в противоположность к контрольной группе, где отмечалась лишь небольшая тенденция к коррекции ПМ (табл. 1);

- достоверное повышение/коррекцию резерва капиллярного кровотока у пациентов основных групп, что отражает самостоятельную патогенетическую роль лазерной терапии для пациентов с хроническими вирусными гепатитами (табл. 1);

- отмечена также нормализация показателей сверхмедленных колебаний (A $\alpha)$, медленных и высокочастотных колебаний амплитудно-частотного спектра в основных группах (рис. 4).

У пациентов, получавших традиционную патогенетическую медикаментозную терапию (І группа), после лечения отмечается тенденция к увеличению доли лиц с нормоциркуляторным типом (НГТМ) до 40 \% исследуемых, однако по-прежнему у большинства пациентов сильны и выражены неблагоприятные патогенетические влияния, что отражено в доминировании патологических типов капиллярного кровотока (рис. 1):

- ГГТМ - 10 \% исследуемых;

- СГТМ - 33,3\%

- ЗСГТМ - 16,7\%.

Активная самостоятельная роль лазерной терапии у пациентов с хроническими гепатитами проявляется в значительном увеличении доли пациентов с нормациркуляторным/оптимальным типом тканевой перфузии и отсутствием в динамике в основных группах пациентов с застойно-стазическим типом (ЗСГТМ).

Изменение гемодинамических типов МЦ у больных хроническим гепатитом на фоне лазерной терапии обусловлено нормализацией функции эндотелия сосудов, формированием баланса вырабатываемых эндотелием нейрогормонов, уменьшением проницаемости сосудистой стенки.

Функциональное соотношение между функцией эндотелия и капиллярными гемодинамическими нарушениями позволяет говорить о возможности использования ЛДФ не только для выявления нарушений перфузии, но и для динамического контроля за функциональной активностью сосудистого эндотелия у больных хроническим гепатитом в ходе лечения.

Таким образом, можно обобщить, что различные методы лазерной терапии улучшают состояние эндотелия, а также способствуют уменьшению нарушений в капиллярном русле у пациентов с хроническими вирусными гепатитами.

\section{Выводы}

1. Концентрация маркеров эндотелиальной дисфункции изменена при хроническом вирусном гепатите.

2. Лазерная терапия нормализует эндотелиальную функцию.

3. Капиллярный кровоток нормализуется при лазерной терапии. 
4. Лазерная терапия представляет собой самостоятельный, независимый, эффективный и безопасный метод патогенетического лечения хронических гепатитов.

\section{Список литературы}

1. Абакумов М.М., Голиков П.П. 2005. Оксид азота и свертывающая система крови в клинике. Вестник РАМН. 10: 53-56.

2. Аксенова И.3., Бурдули Н.М. 2015. Низкоинтенсивная лазерная терапия как метод патогенетической коррекции системы агрегатного состояния крови при хронической обструктивной болезни легких. Лазерная медицина. 19 (3): 23-29.

3. Ахмедов В.А. 2011. Практическая гастроэнтерология. М: МИА, 412 с.

4. Бахтияров Р.3. 2004. Современные методы исследования функции эндотелия. Российский кардиологический журнал. 2: 76-79.

5. Бурдули Н.М., Крифариди А.С. 2009. Влияние низкоинтенсивного лазерного излучения на показатели гемокоагуляции у больных хроническим вирусным гепатитом. Лазерная медицина, 3: 8-14.

6. Васильев А.П., Стрельцова Н.Н., Сенаторов Ю.Н. 2003. Изменение микроциркуляции различных гемодинамических типов у больных стенокардией под влиянием лазерной терапии. Лазерная медицина. 7 (3-4): 16-20.

7. Гейниц А.В., Москвин С.В., Азизов Г.А. 2006.Внутривенное лазерное облучение крови. M., $142 \mathrm{c}$.

8. Гейниц А.В., Цыганова Г.И. 2011. ГНЦ лазерной медицины - четверть века на пути создания лазерных инновационных технологий в медицине. Лазерная медицина. 15 (2): 16-18.

9. Жаров С.Н., Лучшев В.И., Санин Б.И., Трофимова М.Н. 2001. Коррекция микроциркуляторных нарушений в печени у больных вирусными гепатитами с героиновой зависимостью. Эпидемиология и инфекционные болезни. 5: 24-27.

10. Загидуллин Н.Ш., Валеева К.Ф., Гасанов Н.М, Загидуллин Ш.3. 2010. Значение дисфункции эндотелия при сердечно-сосудистых заболеваниях и методы ее медикаментозной коррекции. Кардиология. 5: 44-60.

11. Звягинцева Т.Д., Гриднева С.В. 2005. Современные представления о сосудистом эндотелии в норме и при патологии желудочно-кишечного тракта. Экспериментальная и клиническая гастроэнтерология. 4: 6-12.

12. Ивашкин В.Т., Лапина Т.Л. 2012. Гастроэнтерология. Национальное руководство. Краткое издание. М: ГЭОТАР - Медиа, $462 \mathrm{c.}$

13. Каменская В.Н., Цыганова Г.И., Вяльцева Н.И. 2011. Лазерная медицина в зеркале отечественной научной периодики. Лазерная медицина. 15 (2): 27-27.

14. Козлов В.И. 2006. Система микроциркуляции крови: клинико-морфологические аспекты изучения. Лекция. Регионарное кровообращение и микроциркуляция. 1 (17): 84-101.

15. Козлов В.И., Азизов Г.А. 2011. Лазеры в диагностике и коррекции расстройств микроциркуляции крови. Лазерная медицина. 15 (2): 25-26.

16. Крифариди А.С. 2008. Влияние низкоинтенсивного лазерного излучения на цитокиновую систему, функцию эндотелия сосудов, некоторые показатели гемореологии и микроциркуляции у больных хроническими вирусными гепатитами. Диссертация на соискание ученой степени кандидата медицинских наук. Владикавказ, 164 с.

17. Маколкин В.И., Подзолков В.И., Павлов В.И., Богданова Э.А. 2000. Состояние микроциркуляции при гипертонической болезни. Кардиология. 7: 36-39.

18. Манапова Э.Р., Фазылов В.Х., Хамзина Р.В., Подряднова Т.В. 2005. Патогенетическая эффективность применения лазеротерапии в лечении хронического вирусного гепатита С при коинфекции с ВИЧ. Лазерная медицина. 4: 24-27.

19. Марков Х.М. Оксид азота и атеросклероз. 2011. Оксид азота, дисфункция сосудистого эндотелия и патогенез атеросклероза. Кардиология. 11: 64-74.

20. Пахомов А.Г., Вчерашний Д.Б. 2016. Оценка функции микроциркуляции при лазерном лечении лимфедемы нижних конечностей. Научные ведомости Белгородского государственного университета. Медицина Фармация. Вып. 33, 5 (226): 50-55.

21. Применение лазерной доплеровской флоуметрии в медицинской практике. 1998. Сб. науч. тр. Второго Всероссийского симпозиума. М., 189 с. 


\section{References}

1. Abakumov M.M., Golikov P.P. 2005. Oksid azota i svertyvajushhaja sistema krovi v klinike [Nitric oxide and blood coagulation system in the clinic]. Vestnik RAMN. 10: 53-56.

2. Aksenova I.Z., Burduli N.M. 2015. Nizkointensivnaja lazernaja terapija kak metodpatogeneticheskoj korrekcii sistemy agregatnogo sostojanija krovi pri hronicheskoj obstruktivnoj bolezni legkih [Low-intensive laser therapy as a technique for pathogenic correction of blood aggregate system in patients with chronic obstructive pulmonary disease]. Lazernaja medicina. 19 (3): 23-29.

3. Ahmedov V.A. 2011. Prakticheskaja gastrojenterologija [Practical gastroenterology]. M: MIA, $412 \mathrm{~s}$.

4. Bahtijarov R.Z. 2004. Sovremennye metody issledovanija funkcii jendotelija [Modern methods of endothelial function research]. Rossijskij kardiologicheskij zhurnal. 2: 76-79.

5. Burduli N.M., Krifaridi A.S. 2009. Vlijanie nizkointensivnogo lazernogo izluchenija na pokazateli gemokoaguljacii u bol'nyh hronicheskim virusnym gepatitom [Effect oflow-intensity laserradiation oncoagulationparametersin patients with chronicviral hepatitis]. Lazernaja medicina, 3: 8-14.

6. Vasil'ev A.P., Strel'cova N.N., Senatorov Ju.N. 2003. Izmenenie mikrocirkuljacii razlichnyh gemodinamicheskih tipov u bol'nyh stenokardiej pod vlijaniem lazernoj terapii [Changes in microcirculation of various hemodynamic types in patients with angina under the influence of laser therapy]. Lazernaja medicina. 7 (3-4): 16-20.

7. Gejnic A.V., Moskvin S.V., Azizov G.A. 2006.Vnutrivennoe lazernoe obluchenie krovi [Intravenous laser irradiation of blood]. M., $142 \mathrm{~s}$.

8. Gejnic A.V., Cyganova G.I. 2011. GNC lazernoj mediciny - chetvert' veka na puti sozdanija lazernyh innovacionnyh tehnologij $\mathrm{v}$ medicine [laser medicine-a quarter of a century on the way to the creation of innovative laser technologies in medicine]. Lazernaja medicina. 15 (2): 16-18.

9. Zharov S.N., Luchshev V.I., Sanin B.I., Trofimova M.N. 2001. Korrekcija mikrocirkuljatornyh narushenij v pecheni u bol'nyh virusnymi gepatitami s geroinovoj zavisimost'ju [Correction of microcirculatory disorders in the liver in patients with viral hepatitis with heroin addiction]. Jepidemiologija i infekcionnye bolezni. 5: 24-27.

10. Zagidullin N.Sh., Valeeva K.F., Gasanov N.M, Zagidullin Sh.Z. 2010. Znachenie disfunkcii jendotelija pri serdechno sosudistyh zabolevanija i metody ee medikamentoznoj korrekcii [The value of endothelial dysfunction in cardiovascular disease and methods of its medical correction]. Kardiologija. 5: $44-60$.

11. Zvjaginceva T.D., Gridneva S.V. 2005. Sovremennye predstavlenija o sosudistom jendotelii $\mathrm{v}$ norme i pri patologii zheludochno-kishechnogo trakta [Modern concepts of vascular endothelium in the normal and in the pathology of the gastrointestinal tract]. Jeksperimental'naja i klinicheskaja gastrojenterologija. 4: 6-12.

12. Ivashkin V.T., Lapina T.L. 2012. Gastrojenterologija nacional'noe rukovodstvo kratkoe izdanie [Gastroenterology national guide short edition]. M: GJeOTAR - Media, $462 \mathrm{~s}$.

13. Kamenskaja V.N., Cyganova G.I., Vjal'ceva N.I. 2011. Lazernaja medicina v zerkale otechestvennoj nauchnoj periodiki [Laser medicine in the mirror of Russian scientific periodicals]. Lazernaja medicina. 15 (2): $27-27$.

14. Kozlov V.I. 2006. Sistema mikrocirkuljacii krovi: kliniko-morfologicheskie aspekty izuchenija Lekcija [The system of blood microcirculation: clinica land morphological aspects of the study Lecture]. Regionarnoe krovoobrashhenie i mikrocirkuljacija. 1 (17): 84-101.

15. Kozlov V.I., Azizov G.A. 2011. Lazery v diagnostike i korrekcii rasstrojstv mikrocirkuljacii krovi [Lasers in the diagnosis and correction of microcirculation disorders]. Lazernaja medicina. 15 (2): $25-26$.

16. Krifaridi A.S. 2008. Vlijanie nizkointensivnogo lazernogo izluchenija na citokinovuju sistemu, funkciju jendotelija sosudov, nekotorye pokazateli gemoreologii i mikrocirkuljacii u bol'nyh hronicheskimi virusnymi gepatitami [The effect of low-intensity laser radiation on the cytokine system, vascular endothelial function, and some indicators of hemorheology and microcirculation in patients with chronic viral hepatitis]. Dissertacija na soiskanie uchenoj stepeni kandidata medicinskih nauk., g. Vladikavkaz, $164 \mathrm{~s}$.

17. Makolkin V.I., Podzolkov V.I., Pavlov V.I., Bogdanova Je.A. 2000. Sostojanie mikrocirkuljacii pri gipertonicheskoj bolezni [State of microcirculation in hypertension]. Kardiologija. 7: 36-39.

18. Manapova Je.R., Fazylov V.H., Hamzina R.V., Podrjadnova T.V. 2005. Patogeneticheskaja jeffektivnost' primenenija lazeroterapii v lechenii hronicheskogo virusnogo gepatita $\mathrm{S}$ pri koinfekcii $\mathrm{s}$ 
VICh [Pathogenetic efficacy of laser therapy in the treatment of chronic viral hepatitis $\mathrm{C}$ in co-infection with HIV]. Lazernaja medicina. 4: 24-27.

19. Markov H.M. Oksid azota i ateroskleroz. 2011. Oksid azota, disfunkcija sosudistogo jendotelija i patogenez ateroskleroza [Nitric oxide and atherosclerosis. Nitric oxide, vascular endothelial dysfunction and atherosclerosis pathogenesis]. Kardiologija. 11: 64-74.

20. Pahomov A.G., Vcherashnij D.B. 2016. Ocenka funkcii mikrocirkuljacii pri lazernom lechenii limfedemy nizhnih konechnostej [The microcirculation function in the laser lower extremities lymphedema treatment]. Nauchnye vedomosti Belgorodskogo gosudarstvennogo universiteta. Medicina Farmacija. vyp. 33, 5 (226): 50-55.

21. Primenenie lazernoj doplerovskoj floumetrii $\mathrm{v}$ medicinskoj praktike [Application of laser Doppler flowmetry in medical practice]. 1998. Sb. nauch. tr. Vtorogo Vserossijskogo simpoziuma. M., $189 \mathrm{~s}$.

\section{Ссылка для цитирования статьи For citation}

Бурдули Н.М., Крифариди А.С., Аксенова И.3. 2020. Лазерная терапия в лечении хронических вирусных гепатитов. Актуальные проблемы медицины, 43(1): 5-15. DOI

Burduli N.M., Krifaridi A.S., Aksenova I.Z. 2020. Laser therapy in chronic viral hepatitis treatment. Challenges in Modern Medicine, 43(1): 5-15 (in Russian). DOI 